\title{
Ecological Model and Numerical Research of Gulf of Mexico Hypoxic Zone
}

\author{
Yu Qiao, Xiwen Zhang, Runpeng Zhang, and Junhui Gao
}

\begin{abstract}
This program focuses on the formation process of the hypoxic zone which leads to the death and even extinction of many plant and fish species in the Gulf of Mexico by combining differential equation model and cellular automaton and applied multi -scale method to simulate the formation of the hypoxic zone in the Gulf of Mexico. We first apply cellular method by dividing the map of Gulf of Mexico into 140 times 24 girding on Excel. Then we use difference equation to simulation the formation process. The interaction process among the girding is achieved by cellular automaton. The innovation in this project is that we apply the multi-scale analysis method to simulate the possible hypoxic zone with given geological data and numerical value of the five variables.
\end{abstract}

Index Terms-Gulf of Mexico, hypoxic zone, cellular automaton, multi-scale analysis method.

\section{INTRODUCTION}

Gulf of Mexico is located between the south-east coast of the USA, east of Mexico, part of which is surrounded by land. It connects the Atlantic Ocean, through the Florida channel. At its northern edge are the famous US gulf states of Florida, Alabama, Mississippi, Louisiana and Texas [1]. The Gulf Stream flows from the Gulf of Mexico to north-west Europe. Since 1950, the US government had regulated a set of incentive policy to promote the interregional migration to the Gulf States, which attracted millions of people to the gulf region. Due to the increasing demand of fresh water, energy, and food supply, the Gulf of Mexico eco-system is deteriorating in unprecedented speed. The lethal damage to the environment is the application of modern agriculture techniques, which leads to the outbreak of red tide and consequently leads to the death of fish living in the Gulf of Mexico. In order to resolve this serious ecological damage, we need to know specifically how and where the hypoxic zone occurs. Therefore, we divide this project into three different parts: building a digital map, building a mathematic model, and building a program of Cellular Automaton to stimulate the formation of the hypoxic zone.

\section{MATERIALS AND METHODS}

\section{A. Build Digital Map}

Manuscript received January 11, 2015; revised May 13, 2015.

Yu Qiao, Xiwen Zhang, and Runpeng Zhang are with the Tianyi High School, Jiangsu Province, China (e-mail: qiaolaoye68586076@163.com, 748972551@qq.com,19980922@outlook.com).

Junhui Gao is with Shanghai Center for Bioinformation Technology, Shanghai, China (e-mail: jhgao@ scbit.org).
To build a Cellular Automata [2], we first need to create a digital map to represent the geological landscape of Gulf of Mexico.

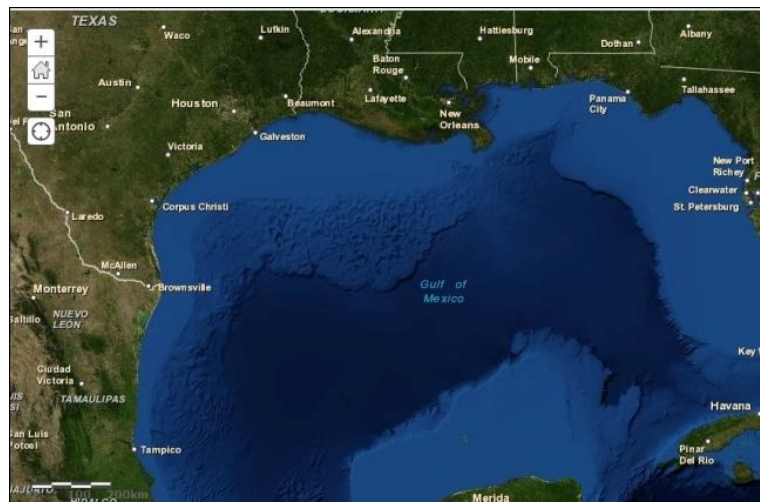

Fig. 1. The geological landscape of Gulf of Mexico [3].

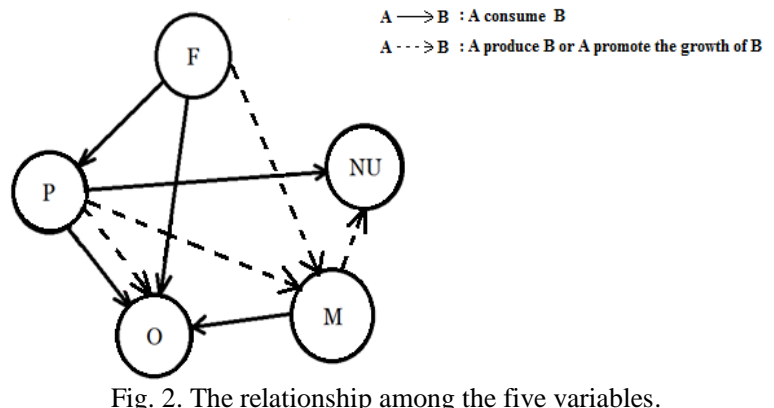

We build the digital map in an Excel file. We begin with adding a graticule of 140 times 40 on the map of the Gulf of Mexico. Then we put number in the pixels we created. We define the number " 1 " as the land, number " 2 " as water and number "3" as the estuary (Fig. 1).

\section{B. Create a Mathematical Model}

Different from traditional mathematical models [4], our research will focus on the change of the density of the fish. We define 5 variables in our mathematical model:

1) Fish, which is represented by "F", consumes phytoplankton(plant) and oxygen;

2) Plant, which is represented by "P", consumes oxygen, but produces more oxygen by photosynthesis. It also consumes nutritive salt and provides food for the fish and microorganism;

3) Oxygen, which is represented by "O", is consumed by all organisms;

4) Microorganism, which is represented by " $M$ ", consumes oxygen and decomposes plants, thus producing nutritive salt.

5) Nutritive salt, which is represented by "NU", promotes the growth of the plants. The main elements in the 
nutritive salt are nitrogen and phosphorous.

We create a picture to clearly describe the relationship among the five variables mentioned above (Fig. 2).

\section{Relationship among the Five Variables}

We assume that in a typical area in the ocean, the five variables influence one another along the change of time in a particular format. So, we can approximately deduce the changing condition of the organisms in the whole marine system by considering the relationship among these five variables in this particular region.

Therefore, we start to look for the relationship among the five variables and attempt to demonstrate it with mathematical expressions.

We didn't figure out the confusing situation until we read a book about physical oceanography. Then we understand the importance of deducing empirical equation and parameters. As the book mentioned, the complexity of a biological model is determined by biodiversity and interaction among organisms. In the matter of ecosystem dynamics, to pursue the integrity of system by blindly adding variables will significantly reduce the reliability of the model.

A correct mathematical equation should be able to describe these complicated organic processes in a simplest form. In a biological model, many variables have a nonlinear relationship so that it is difficult to find the accurate mathematical formula which describes these processes. However, in most cases, these empirical equations are based on the fitting results that are observed in some marine region. Strictly speaking, they are only suitable for some particular marine regions and time periods. When the official documents are not available, choosing any of the empirical equations blindly may also affect the reliability of the model. The principle is: If there exists several mathematical equations, we should choose the easiest expression with the least coefficients [5].

\section{Derivation Process}

\section{1) Fish}

First, we consider the main research subject - fish.

We assume that the growth rate of fish is proportional to its feeding - the consumption of fish is equal to its reproduction (baby fish). However, of course, it's impossible for the fish to absorb all the nutrition of the plants; hence, we define a constant " $\alpha$ " to represent the absorptivity of the nutrition. Also, fish cannot be fed limitlessly. The plants that are fed will reach a saturation value and the amount of food must be limited by the total amount of plants, thus we use such an expression to represent this kind of relationship: The amount of food $=\alpha^{*}\left[1-e^{\wedge}(\lambda P)\right]^{*} F$ (which is also called the Ivlev equation). $\lambda$ is the semi-saturation coefficient of the herbivorous fish. $P$ is the amount of plants and $F$ is the amount of fish. At the same time, fish will also die, thus we assume that some part of the fish population will naturally die after a unit of time. Assume the death rate as $\beta$. We use derivative to express the natural growth rate of fish, which is represented by the equation below [6]:

$$
\frac{d F}{d t}=\alpha^{*}\left[1-e^{\wedge}(\lambda P)\right]^{*} F-\beta F
$$

At the same time, we assume the amount of fish is proportional to the amount of oxygen. More generally, we assume all the organisms in the marine system will consume certain amount of oxygen that is proportional to the amount of the organisms. So that how the amount of oxygen will change relative to the previous unit of time is expressed below:

$$
\frac{d F}{d t}=\alpha^{*}\left[1-e^{\wedge}(\lambda P)\right]^{*} F-\beta F+\tau \frac{O-O_{c}}{O_{c}} * F
$$

\section{2) Plants}

First we consider how the fish is fed on plants. We only need to subtract the amount of food calculated before:

$$
\frac{d P}{d t}=-\alpha^{*}\left[1-e^{\wedge}(\lambda P)\right]^{*} F
$$

Similarly, add the effect of the amount of oxygen to the amount of plants:

$$
\frac{d P}{d t}=-\alpha *\left[1-e^{\wedge}(\lambda P)\right]^{*} F+\tau \frac{O-O_{c}}{O} * P
$$

The growth of plants is decided by the effect of both photosynthesis and nutritive salt, thus we use the Michaelis-Menten equation to describe the nutritive salt-autotrophic phytoplankton model in this biological system. In the equation, $f(I)$ is the function of light intensity to control the photosynthesis process. $V m$ is the maximum growth rate of the phytoplankton. $K_{n}$ is the semi-saturation concentration in the process of assimilation of nutritive salt.

$$
\frac{d P}{d t}=-\alpha *\left[1-e^{\wedge}(\lambda P)\right]^{*} F+\tau \frac{O-O_{c}}{O} * P+f(I) * \frac{V_{m} N}{K_{N}+N} P
$$

Finally we subtract the amount of natural death of plants. $\delta$ is the natural death ratio of the plants:

$$
\frac{d P}{d t}=-\alpha *\left[1-e^{\wedge}(\lambda P)\right]^{*} F+\tau \frac{O-O c}{O} * P+f(I) * \frac{V_{m} N}{K_{N}+N} P-\delta P
$$

\section{3) Oxygen}

Marine organisms consume oxygen.

$$
\frac{d O}{d t}=-\varepsilon_{f} F-\varepsilon_{P} P-\varepsilon_{m} M+\gamma P
$$

In the equation, $\varepsilon_{f}, \varepsilon_{p}, \varepsilon_{m}$ represent the speed of oxygen consumption of fish, plants and microorganisms, respectively. $\gamma$ represents the speed of production of oxygen by photosynthesis.

\section{4) Microorganism}

Microorganism is released mainly by the death of plankton and the physiological reaction by secretion. Now we assume the source of microorganism is mainly the three below:

1) The death of fish;

2) The death of plants;

3) The remain of the food of fish that they don't absorb completely.

Based on the above we derive the formula: 


$$
\frac{d M}{d t}=\mu\left\{\beta F+\delta P+(1-\alpha) *\left[1-e^{\wedge}(\lambda P)\right]\right\}
$$

In the equation, $\mu$ is the ratio of change from fragment to microorganism. The way that oxygen affects the process is the same as above:

$$
\frac{d M}{d t}=\mu\left\{\beta F+\delta P+(1-\alpha) *\left[1-e^{\wedge}(\lambda P)\right]\right\}+\tau \frac{O-O_{c}}{O} * M
$$

\section{5) Nutritive salt}

Similarly, we use Michaelis-Menten equation to describe the nutritive salt-autotrophic phytoplankton model in this biological system [6]. However, microorganisms can also decompose to produce nutritive salt.

$$
\frac{d N}{d t}=-f(I) * \frac{V_{m} N}{K_{N}+N} P+\omega M
$$

In the equation, $\omega$ represents the ratio of decomposition of microorganisms.

After we finish the mathematical model, the next step is to find out the parameter and simulate the specific changing process by the program.

\section{E. The Adjustment of Parameter}

Though we can derive the relationship in theoretical way

\begin{tabular}{|c|c|c|}
\hline Symbol & Meaning & Value \\
\hline$\alpha$ & Fish's absorptivity of the nutrition & 0.6 \\
\hline$\lambda$ & $\begin{array}{c}\text { Semi-saturation coefficient of the } \\
\text { herbivorous fish }\end{array}$ & 0.035 \\
\hline $\begin{array}{l}\beta \\
0.005\end{array}$ & Natural death rate of the fish & \\
\hline$F(I)$ & Coefficient of light intensity & 0.8 \\
\hline$V_{m}$ & $\begin{array}{l}\text { Maximum growth rate of the } \\
\text { phytoplankton }\end{array}$ & 0.2 \\
\hline$K_{N}$ & $\begin{array}{l}\text { Semi-saturation concentration } \\
\text { in the process of assimilation of } \\
\text { nutritive salt }\end{array}$ & 0.05 \\
\hline $\begin{array}{l}\delta \\
0.005\end{array}$ & Natural death ratio of the plants & \\
\hline$\varepsilon_{f}$ & $\begin{array}{l}\text { The speed of oxygen consumption of } \\
\text { fish }\end{array}$ & 0.1 \\
\hline$\varepsilon_{p}$ & $\begin{array}{c}\text { The speed of oxygen consumption of } \\
\text { plants }\end{array}$ & 0.1 \\
\hline$\varepsilon_{m}$ & $\begin{array}{l}\text { The speed of oxygen consumption of } \\
\text { microorganism }\end{array}$ & 0.1 \\
\hline$\gamma$ & $\begin{array}{l}\text { The speed of production of oxygen } \\
\text { by photosynthesis }\end{array}$ & 0.15 \\
\hline$\mu$ & $\begin{array}{l}\text { The rate of change of fragment that } \\
\text { changes into microorganism }\end{array}$ & 0.8 \\
\hline$\omega$ & $\begin{array}{l}\text { The rate of decomposition of } \\
\text { microorganism }\end{array}$ & 0.8 \\
\hline$\tau$ & $\begin{array}{l}\text { The influence rate of oxygen on } \\
\text { organism }\end{array}$ & 0.1 \\
\hline$O_{c}$ & Standard constant of oxygen & 1.0 \\
\hline
\end{tabular}
but still have problems: We only have a vague concept about how to control the mathematical model to run.

Therefore, we searched for some papers on the Internet and synthesized the parameters in these papers. After we substitute the parameters, we can adjust them by observing the real condition of model running (Table I).

\section{F. Multi-scale Numerical Simulation}

What we simulate is the changing number of species in a particular marine region. We know that in the marine system, different regions are affected by different factors, thus the condition of the species is also different. With that in mind, we use the cellular automaton system, which distributed the cells in the uniform gridding to consist of the derivation of the dynamic system through simple interaction. Therefore, the process of simulation is mainly divided into two parts: 1 . The simulation of species in each cell internally; 2 . The interaction among the cells.

We use the floating point map which is made in Arcgis and use different colors to represent the points in Delphi. The map is cut into units of $140 \times 40$, and use 1,2,3,4 to represent land, ocean, river and origin of river, respectively. In a Programming Software, we first use memo to guide into the map in txt format, and then compile a program to cut the character string in each line. Finally we represent each type of character by different colors, which will reveal in Fig. 3.

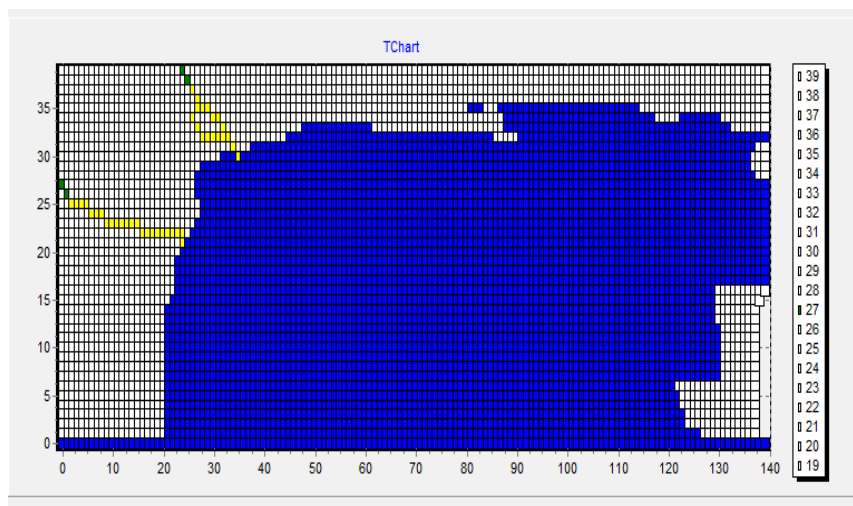

Fig. 3. Map with different colors representing different landscape.

Here is our simulation method:

1) The simulation of density change inside the cell

We divide the whole gulf area into units of $140 \times 40$, and each of these small areas represents a cell. Inside the cell are five elements interacting with each other. We have deduced and encoded the relationship between our study subjects.

2) The interaction between cells

Due to the irregular motion of the molecules, the distributions of marine species have gone on an irreversible process from uniformity to non-uniformity, which is our basic principle in the simulation process. To stabilize the result of the simulation, we assume that there is enough time for marine species to go through this process. As the simulation begins, we assume that the amounts of variables in all the cells are equal. Firstly we choose a cell randomly, and then, randomly choose another cell around the cell (upward, downward, leftward and rightward) that we initially chose and distribute the amount of species in the two cells at a particular ratio. Repeating the process mentioned above, that is, randomly choose a cell and interact with the cell around it, we can successfully simulate the change of marine species.

\section{RESULT AND DISCUSSION}

Donald Scavia1and Mary nne Evans have used the model to forecast the hypoxic volume of the Chesapeake Bay [7]. Here, we set the initiative values of the five variables and equations including the particular parameters to show the 
density distribution of the fish. Fig. 4 and Fig. 5 are the density distribution diagrams after running the program.

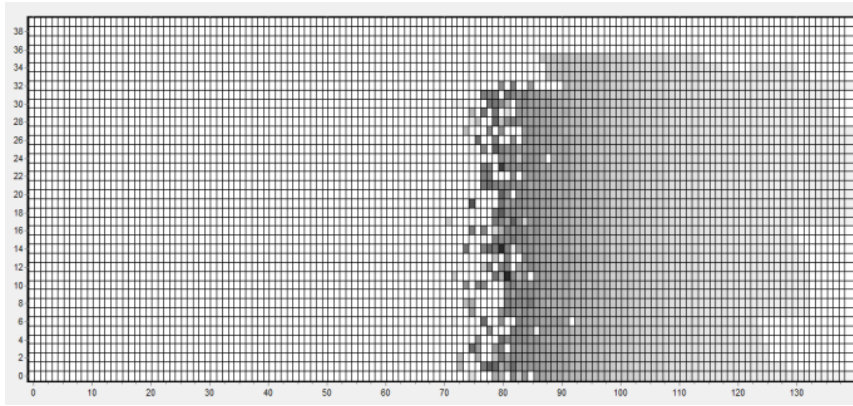

Fig. 4. Density distribution of fish when the amount of nutritive salt in the river is 250 .

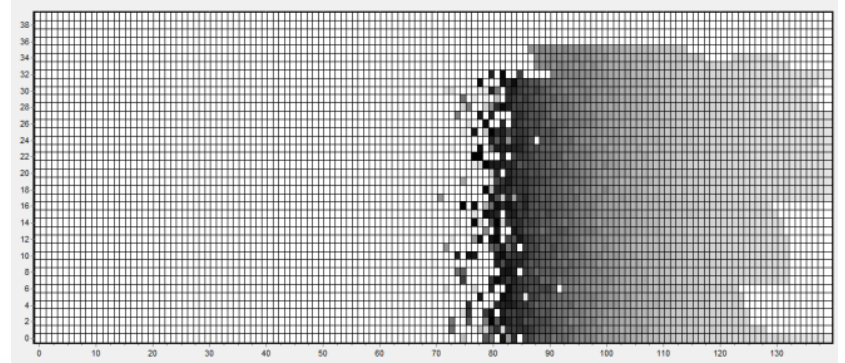

Fig. 5. Density distribution [8] of fish when the amount of nutritive salt in the river is 500 .

In the two graphs, the darker color means the bigger number of fish that die of hypoxic in that area. From the graphs we can clearly see that as the density of the nutritive salt increase, the hypoxic area enlarges, thus causing the increasing death of fish.

Finally, we successfully simulate the process of formation of the hypoxic zone.

\section{A. Some Deficiencies}

1) The land form is divided into $140 \times 40$ cells, which is not accurate enough to establish models and simulate the changes.

2) Some parameters are not accurate enough; some other parameters are derived from empirical facts. When we simulate the changes and try to tweak the empirical parameters, it seems that almost all parameters can result in a ideal simulation graph. Therefore, the empirical parameters need further examination.

\section{B. Comparison between the Simulation Methods}

TABLE II: SIMULATION METHOD COMPARISON

\begin{tabular}{cccc}
\hline \hline Method & $\begin{array}{c}\text { Differential } \\
\text { equation and } \\
\text { difference } \\
\text { equation }\end{array}$ & $\begin{array}{c}\text { Cellular } \\
\text { automaton }\end{array}$ & $\begin{array}{c}\text { Multi-scale } \\
\text { analysis }\end{array}$ \\
\hline Limitation & $\begin{array}{c}\text { The area must } \\
\text { be regular }\end{array}$ & $\begin{array}{c}\text { Flexible with } \\
\text { no limitation }\end{array}$ & $\begin{array}{c}\text { Flexible with } \\
\text { no limitation }\end{array}$ \\
\hline $\begin{array}{c}\text { Simulation } \\
\text { speed }\end{array}$ & Fast & Slow & Medium \\
\hline \hline
\end{tabular}

\section{CONCLUSION}

In this project, we have successfully researched the factors that cause the hypoxic areas in the Mexico Gulf using the multistage analysis.

Multi-scale analysis has both the flexibility of cellular automaton and the high simulation speed of the method of differential equation and difference equation. Therefore, it has the potential to be widely adopted.

Throughout research, we conclude that the excessive emission of nutritive salt is the major factor that causes the hypoxic areas in the Mexico Gulf.

\section{ACKNOWLEDGMENT}

The accomplishment of the project was also supported by two professors from Florida University: Dr. Mary Barzee and Dr. Kara Radabaugh. Thanks to their help on the proceeding of this project.

\section{REFERENCES}

[1] (2003). Baiscconcept of the Gulf of Mexico. [Online]. Available: http://baike.so.com/doc/6143795.html

[2] J. V. Neumann, Theory of Self-Reproduction Automats, Urbana, IL University of Illinois Press, 1966, p. 35.

[3] Map of the Gulf of Mexico. [Online]. Available: http://image.so.com/v?ie=utf- $8 \& q=$ gulf + of + mexico $\&$ src=tab_se $\&$ fro murl=http $\% 3 \mathrm{~A} \% 2 \mathrm{~F} \% 2$ Fwww.ssd.noaa.gov\%2Fimagery\%2Fgmex.ht ml\#multipl0\&dataindex=110\&id=8211f12db89b532dbd39aa43e0aca a4a\&lightboxindex $=5 \&$ iteminde $=0$

[4] L. Ye, "Mathematic model based on red tide and its application on Bo Sea," pp. 27-28, Tianjin University, 2007.

[5] C. Chen, The Marine Ecosystem's Dynamics and Model, Higher Education Press, May 1, 2003, ch. 5.1.

[6] C. Chen, The Marine Ecosystem's Dynamics and Model, Higher Education Press, May 2, 2003, ch. 5.4.

[7] J. Feng, "Study based on red tide ecological system and it spatial distribution forecast," pp. 17-34, Tianjin University, 2003.

[8] D. Scavia and M. Evans, "Chesapeake bay hypoxic volume forecasts and results," University of Michigan US Geological Survey - Great Lakes Science Center, 2013, p. 3.

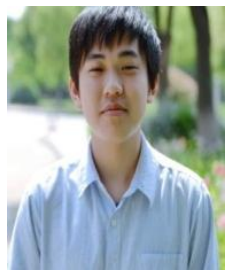

Yu Qiao is currently a student in Tianyi High School International Department. He had attended Duke Talent Identification Program in Florida New College, USA in 2014. He is now working on a research pape about Gulf of Mexico Hypoxia zone. He had also attended the High School Innovation Competition in China.

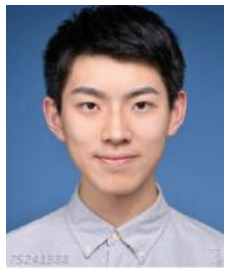

Xiwen Zhang is currently a student in Tianyi High School International Department and is working on a research paper about Gulf of Mexico Hypoxia zone. $\mathrm{He}$ had also attended High School Innovation Competition. Mr. Xiwen Zhang focuses on mathematics and computer programming. He had attended FTC Competition.

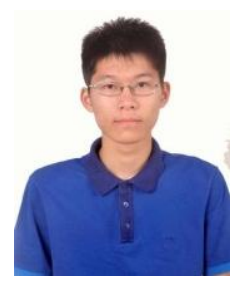

Runpeng Zhang is currently a student in Tianyi High School International Department. He had attended the High School Innovation Competition. He focuses on building this program on collecting data.

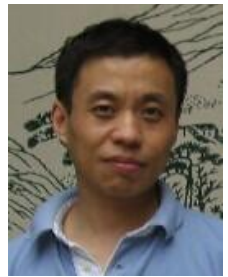

Junhui Gao is a research associate of Shanghai Center for Bioinformation Technology. He got his B.Sc in ecology at East China Normal University, and the M.Sc in computer science at Shanghai Jiao Tong University. Currently his researches focus on computer simulation for phenomenon of ecology (food chain, food net) and molecular systems biology, deep sequencing data analysis, computer aided drug design. 